\title{
Correspondence
}

The Editor, Journal of Glaciology

SIR,

\section{Why calculated basal drags of ice streams can be fallacious}

Whillans and Van der Veen (1993) have performed valuable measurements of surface strains on Ice Streams B and C, Antarctica. Unfortunately, their paper does not present the raw numerical data which, as unquestionable fact, deserve to be put at the disposal of the entire scientific community. Following a bad habit, which appears to have become commonplace in glaciological literature, Whillans and Van der Veen have published only the results inferred from these field data. In particular, they have published an inferred basal drag, which is found to be negative in some places on Ice Stream B. I believe this negative drag is a nonsensical result of questionable assumptions which underlie Whillans and Van der Veen's analysis of the data. The speculative explanations of the negative drag offered by Whillans and Van der Veen may therefore be of doubtful validity.

In my opinion, the untenable result of Whillans and Van der Veen's analysis, i.e. negative basal drag, comes from the assumption, introduced by Nye in the 1960s, that horizontal strain rates are uniform through the ice column. As Whillans and Van der Veen have recognized, the cold upper layer of the ice stream acts as a stress guide - as an almost rigid "lid" which caps the soft, warmer ice layers below. Consequently, the strain rates in the upper layer should be much smaller than in the lower layers. Streamlines of ice-stream flow thus smooth readily from the bottom of the ice stream upwards. This behaviour is typical in polar ice sheets, as internal layering revealed by VHF sounding has shown (Robin and others, 1977).

Whillans and Van der Veen have indicated that the thickness of Ice Stream B along the entire grid varies between 1020 and $1070 \mathrm{~m}$, and that the forward velocity is about $450 \mathrm{~m} \mathrm{a}^{-1}$. When the thickness varies by $20 \mathrm{~m}$ only, a material point at the surface moves away from or closer to the bottom by $450 \times(20 / 1000)=9 \mathrm{~m} \mathrm{a}^{-1}$. The mean vertical strain rate is then $9 \mathrm{~m} \mathrm{a}^{-1} / 1000 \mathrm{~m}=9 \times$ $10^{-3} \mathrm{a}^{-1}$, and it is concentrated in the lower soft layer. Incompressibility requires that the horizontal strain rate in the direction of flow be of the same order (with opposite sign) as the vertical strain rate. The horizontal strain rate near the bed of the ice stream is hence likely to be one order of magnitude greater than the horizontal strain rate measured at the ice-stream surface, which is only of the order of $10^{-3} \mathrm{a}^{-1}$.

The soft basal layer should cope with most of the strains that fast sliding over a rough bed can generate. When the bed elevation increases, basal ice velocity should increase much more than the measured velocity in the nearly rigid "lid" at the surface of the ice stream. The assumption of depth-independent strain rates holds more or less in the cold upper layer but not at all in the warm lower layer. In the lower layer, there can be local extrusion flow over the bumps in the bed (as in Nye's model of a glacier sliding over a bed with sinusoidal bumps). This local extrusion subjects the upper lid to a negative drag which may be reflected in Whillans and Van der Veen's data.

In my opinion, what Whillans and Van der Veen have calculated is not the basal drag but more or less the shear stress that the rapidly deforming lower layer exerts on the stiffer upper layer in response to basal topography. In the lower layer, horizontal strain rates and the corresponding shear stresses are not depth-independent. Although the horizontal shear stress at the very bottom is always positive, in places it may have negative values at some distance above the bed. As recognized by Whillans and Van der Veen, their analysis of the surface strain-rate data misses any oscillation of the stress in the lower layer, where it is small, because their analysis averages the stresses and the resisting forces along a vertical.

Of course, precise numerical calculations that account for a depth-dependent viscosity would give more weight to my heuristic explanation, but I am retired and leave this task to younger people in possession of all the pertinent field data. (A word of advice: this more complex inverse problem cannot be solved without assuming some kind of sliding law at the bed, even if this law has some parameters that need to be adjusted.)

It is fortunate that the method of Van der Veen and Whillans (1989) has led to an absurdity which Whillans and Van der Veen (1993) were courageous enough to publish. Without the clear example of how a questionable assumption can upset the interpretation of perfectly satisfactory data, other investigators would perhaps unwisely trust their method. Many other attractive, simplified methods of data analysis published in the 1960s and 1970s suffer from the same flawed assumption but without generating the diagnostic consequences of an absurd result. These methods have therefore become embedded in standard glaciological knowledge. Their flawed assumptions are taken for granted by young scientists who wish to build a more general understanding of non-linear continuum mechanics atop the perhaps shaky platform that these earlier methods provide. We ought to be more demanding about the validity of the assumptions on which simplified solutions are grounded. To quote published papers, where they have already been used, should not alone be a justification.

\section{Laboratoire de Glaciologie et Géophysique LOUIS LLIBOUTRY de l'Environnement du CNRS, \\ Université Joseph Fourier, \\ 38402 Saint-Martin-d'Hères Cedex, France}

17 March 1994 and in revised form 26 April 1994 


\section{REFERENCES}

Robin, G. de Q., D.J. Drewry and D. T. Meldrum. 1977. International studies of ice sheet and bedrock. Philos. Trans. R. Soc. London, Ser. B, $279(963), 185-196$.

Van der Veen, C.J. and I. M. Whillans. 1989. Force budget: I. Theory and numerical methods. f. Glaciol., 35(119), 53-60.

Whillans, I. M. and C.J. van der Veen. 1993. Patterns of calculated basal drag on Ice Streams B and C, Antarctica. J. Glaciol., 39 (133), $437-446$.

SIR,

\section{Reply to Lliboutry's letter "Why calculated basal drags of ice streams can be fallacious"}

Professor Lliboutry (1995) suggests that there is a deep layer of soft ice extruding ahead of the main glacier and that our study discovered the drag imparted by this deep ice, rather than the drag at the very bottom of the glacier. In this letter, we show that considerations of continuity do lead to inferred deep strain rates that are different from those at the surface, in line with Professor Lliboutry's suggestion, but the stresses associated with this extrusion flow are very small, too small to affect our analysis in an important way. Extrusion flow may be an attractive idea but it cannot account for the unusual result of calculated reverse basal drag.

In Whillans and Van der Veen (1993), we combined calculations of the effects of gravity with forces computed from strain rates measured at the glacier surface. The strain rates pertain to the upper, cold and strong part of the glacier. Forces on the bulk, the sides and base of a column through the glacier must sum to zero, thus the shear stress on the base of the column can be estimated. To our surprise, there are places on Ice Stream B, Antarctica, where the calculated basal drag enhances, rather than retards, glacier motion.

Lliboutry also suggests that deep ice can squeeze ahead, between the main body of ice above and the bed below, to the extent that the gross dynamics of the glacier is affected. Extrusion flow on a very large scale was discredited by Nye (1952) but the possibility of extrusion flow in restricted regions remains open. If it does occur, then faster ice at depth would exert a drag on the ice above in the opposite sense to that normally expected for glacier flow.

A full discussion of the possible importance of extrusion flow should consider the rate of deformation of the extruding layer, the cause and the forces involved. The cause may be large pressure on the upglacier side of an obstruction and small pressure on the down-glacier side. The motion due to this pressure gradient can be modeled following the method of Hutter and others (1981), as has been done for cold over warm ice in Greenland (Whillans and Jezek, 1987). We doubt that significant extrusion can be predicted following such a line of investigation. However, let us set aside the question of the possible cause of extrusion and conduct a simpler analysis by estimating the magnitude of extrusion from measured strain rates and considerations of volume continuity. Using this estimate, we find in the next paragraph that this possibly forward-extruding ice can exert a drag of $7.4 \mathrm{kPa}$ on the ice above. This is not sufficient to explain the anomalous basal drag of about $-100 \mathrm{kPa}$ calculated in the work under discussion.

The details of the calculation of the effect of extrusion flow follow.

\section{KINEMATICS}

Overall horizontal flow divergence must accord with along-flow changes in width and thickness of the ice stream and any mass imbalance. This regional horizontal divergence is given by the mean sum of horizontal normal strain rates, which is about $-1.0 \times 10^{-3} \mathrm{a}^{-1}$ (Whillans and Van der Veen, 1993; Hulbe and Whillans, 1994). Local values of horizontal divergence at the surface range from $-6.3 \times 10^{-3} \mathrm{a}^{-1}$ to $2.6 \times 10^{-3} \mathrm{a}^{-1}$. From these numbers, we use the round value of $5 \times 10^{-3} \mathrm{a}^{-1}$ for the fluctuation. There are no correlating fluctuations in width, thickness or mass balance, so there must be corresponding reverse normal strain rates at depth. These special strain rates are likely to occur in the deepest, warmest and hence softest ice. Suppose that the bottom $10 \%$ of the thickness contains this mobile ice. Then the reverse deep normal strain rates must be minus ten times the surface fluctuation, or about $\pm 5 \times 10^{-2} \mathrm{a}^{-1}$. This estimate is similar to Lliboutry's. (Such deep strain rates have little effect on the total budget of forces discussed in Whillans and Van der Veen (1993) because they occur in weak ice and perhaps because they lie beneath the applicable column for calculation.)

\section{STRESSES}

The stress that causes this strain rate is $\pm 74 \mathrm{kPa}$ (in which the constitutive relation $\sigma_{i j}{ }^{\prime}=B \dot{\varepsilon}_{\mathrm{e}}^{1 / n-1} \dot{\varepsilon}_{i j}$, in the usual notation, is used, with $n=3, \dot{\varepsilon}_{\mathrm{e}} \approx 5 \times 10^{-2} \mathrm{a}^{-1}=\dot{\varepsilon}_{i j}$ and a rate factor of $B=200 \mathrm{kPa}^{\frac{1}{3}}$ appropriate for ice near the melt temperature, as in Hooke (1981). Caution must be exercised because the constitutive relation has not been properly tested.) The value of $\pm 74 \mathrm{kPa}$ is the special normal stress in the deep layer that might be pushing or pulling ice to or from another site.

\section{STRESS GRADIENTS}

This stress may vary from site to site. The distance to consider for this variation is $2000 \mathrm{~m}$, the size of the regions of calculated negative drag. Thus, there can be gradients in normal stress of $2 \times 74 \mathrm{kPa} / 2000 \mathrm{~m}$. (This is a gradient in deviatoric normal stress. The full stress gradient is similar.)

\section{DRAG ON TOP OF EXTRUDING LAYER}

Supposing that the extruding layer is about $100 \mathrm{~m}$ thick $(10 \%$ of the ice thickness), and that there is no friction on the underside of the extrusion, the extrusion is mechanically opposed by drag with the ice above. A simple budget of forces for this extruding layer yields a drag of $7.4 \mathrm{kPa}$ between the extruding layer and the ice above it. This is the number noted earlier.

Being stimulated by Lliboutry's (1995) letter, and continuing to neglect a quantitative consideration for the cause, we also considered the possibility of faster 